$\begin{array}{cc}\text { Esta obra está sob o direito de } \\ & \text { Licença Creative Commons } \\ \text { Atribuição 4.0 Internacional. }\end{array}$

\title{
DIREITO FUNDAMENTAL À ALIMENTAÇÃO
}

\author{
Júlia Cláudia Tenório ${ }^{1}$ \\ Suzana Peixoto de Araújo ${ }^{2}$ \\ Marcelo Henrique Santos ${ }^{3}$ \\ Betijane Soares de Barros ${ }^{4}$
}

\section{RESUMO}

É fato notório que grande parte da população brasileira ainda não tem acesso à alimentação como um direito fundamental. O sistema alimentar é constituído por um conjugado de pessoas e organizações como: agricultores, familiares, atravessadores, imensos empreendimentos, varejistas e consumistas os quais se interagem de forma desproporcional, pois possuem recursos e competências econômicas inteiramente diferenciadas. A Justiça Alimentar é um conceito aberto que se refere ao modo como são difundidos e distribuídos os benefícios e os conflitos negativos do modelo socioeconômico de produção, distribuição e consumo de alimentos. $\mathrm{O}$ combate pela construção de um modelo alimentar mais justo e democrático é um processo plural, coletivo e incompleto e, portanto, pode se manifestar em diferentes níveis e práticas sociais e políticas. Mais do que uma opinião contemplativa, a Justiça Alimentar se assegura concretamente a partir de conflitos características que se consolidam em diferentes campos. Nesse sentido, a Justiça Alimentar pode se manifestar no debate sobre os sistemas de produção agrícola, na discussão sobre o papel do Estado no fomento aos circuitos curtos de produção ou na disputa sobre medidas regulatórias capazes de diminuir o acesso aos alimentos ultra processados, de modo a construir um ambiente alimentar mais digno e saudável. Portanto, o ingresso ao alimento, atravessado de família a família por meio de geração, tem de ser garantido a todas as mães, sem distinção, a fim de que tenham capacidade gerar filhos bem alimentados, crianças e adolescentes saudáveis e, em decorrência, adultos e idosos com estrutura física que lhes consinta ter força para o trabalho, para seus serviços em geral, para o lazer, colocando-os num patamar que lhes consinta ficar imune a toda fatalidade de enfermidades.

Palavras-chave: Alimentação. Direito fundamental à alimentação. Segurança alimentar e nutricional.

\footnotetext{
1 Mestranda do Curso de Pós-Graduação em Saúde Pública, Absoulute Christian University. Email: suzanapeixoto123@hotmail.com.

2 Mestranda do Curso de Pós-Graduação em Saúde Pública, Absoulute Christian University. Email: suzanapeixoto123@hotmail.com.

3 Mestrando do Curso de Pós-Graduação em Saúde Pública, Absoulute Christian University. Email: drmarcelo_psf_odonto@yahoo.com.br.

${ }^{4}$ Doutora em Ciências da Educação (Faculdade de Ciências, Letras e Educação do Paraná). Doutora em Ciências da Saúde (Absoulute Christian University). Mestre em Ciências da Saúde (UFAL). Diretora do IMAS.
} 


\section{INTRODUÇÃO}

O direito fundamental à alimentação é definido como sendo o direito ao acesso regular e permanente à alimentação suficiente e adequada para uma vida digna e livre (MACEDO, 2014).

A trajetória do direito à alimentação no Brasil é considerada recente, apesar do Brasil sempre ter constado como signatário de tratados internacionais de direitos humanos relacionados ao direito à alimentação no mundo, entre eles pode-se citar a Declaração Universal dos Direitos Humanos de 1948, o Pacto Internacional dos Direitos Econômicos, Sociais e Culturais (PIDESC) e a Convenção Internacional dos Direitos da Criança CIDC (DIAS, 2015).

Todos esses tratados estão diretamente ligados ao direito à alimentação universal, contudo no Brasil a garantia desse direito é considerada contemporânea, pois somente em 1999 foi aprovada a política Nacional de Alimentação e Nutrição (PNAN). Essa política foi decorrente de grandes esforços na busca da proteção e promoção aos direitos humanos referentes à saúde e à alimentação, pois ambos caminham juntos.

Outro marco responsável pela consolidação do direito à alimentação no Brasil foi a aprovação da Lei orgânica de segurança Alimentar e Nutricional (LOSAN) em 05 de dezembro de 2006. A aprovação dessa lei foi fundamental para que posteriormente tenha sido instaurado o Sistema de Segurança Alimentar e Nutricional (SISAN) que tem como objetivo criar e implementar políticas e planos de segurança alimentar e nutricional, estimular a integração entre o governo e a sociedade civil (MACEDO, 2014).

Dando continuidade a trajetória do direito à alimentação no Brasil, em 2010 foi promulgada a EC n 64/2010, que instituiu no $\operatorname{artigo} 6^{\circ}$ da Constituição Federal, o direito à alimentação.

A princípio, o direito à alimentação era considerado consequência de outros direitos mais abrangentes, como o direito à vida (VALENTE, 2012). Ao incluir expressamente o direito à alimentação, através da $\mathrm{EC} \mathrm{n}^{\circ}$ 64/2010, no rol de direitos fundamentais, é notório que o tema passou a ser tratado com prioridade no Brasil, pois o direito tornou-se positivado na carta magna. Tornou-se um direito inalienável e exigível de concretização pelo Estado (DELDUQUE, 2014).

A Constituição brasileira de 1988 menciona o direito à alimentação no rol dos Direitos Sociais, porém enfatiza o princípio da dignidade da pessoa humana já em seu 
artigo $1^{\circ}$, inciso III, como um dos princípios da República Federativa do Brasil. Ocorre que só se pode falar em "dignidade da pessoa humana" se seus direitos fundamentais forem, de fato, plenamente assegurados (SENADO FEDERAL, 2019).

A Lei $\mathrm{n}^{\circ} 8.080$ de 19 de setembro de 1990, reafirma a saúde como um direito fundamental do ser humano, devendo o Estado prover as condições indispensáveis para seu exercício integral, através da reformulação e execução de políticas econômicas e sociais (DIÁRIO OFICIAL DA UNIÃO, 2019).

Dentre as condições indispensáveis, no tocante a este estudo, destaca-se a Política Nacional de Alimentação e Nutrição, recentemente atualizada pela Portaria $\mathrm{n}^{\mathrm{o}} 2.715$, de 17 de novembro de 2011, segundo a qual, para a afirmação plena dos potenciais de crescimento e desenvolvimento do ser humano, a alimentação e nutrição são requisitos básicos, necessários para uma vida com qualidade e garantia de cidadania (MINISTÉRIO DA SAÚDE, 2011).

O Encontro Nacional de Segurança Alimentar e Nutricional, promovido pelo Conselho Nacional de Segurança Alimentar e Nutricional (CONSEA), em Brasília (2006), realizou um balanço das iniciativas governamentais, constatando que, apesar dos avanços obtidos, a segurança alimentar e nutricional da população brasileira ainda carece de ações prioritárias do Poder Público (LEÃO,2017).

Os indicadores de saúde e nutrição refletem as desigualdades de renda e raça que ainda persistem no país: mulheres negras e de baixa renda apresentam maiores percentuais de doenças crônicas quando comparadas a mulheres, da mesma idade, brancas e de renda mais alta. Entre os homens, a obesidade está mais presente entre os de renda mais alta, embora cresça em todos os estratos. O desenvolvimento econômico deve ser acompanhado pelo setor saúde para que as populações que tenham incremento de renda também tenham melhorias de acesso e condições de saúde (BRASIL, 2013).

Conforme conhecimento notório pode-se afirmar que a carência alimentar e nutricional compromete seriamente o desenvolvimento da criança, do adolescente e também do adulto idoso de tal forma que, por toda a vida, sofrerão as consequências de uma inadequada promoção de hábitos saudáveis de ingestão alimentar, atingindoos não só nos aspectos físicos, mas emocionais e intelectuais.

Os educandos por sua vez, almejam, sobretudo, ver sentido nos conteúdos trabalhados pelos docentes nas diversas disciplinas e as suas autênticas necessidades pessoais e no convívio com os seus 
semelhantes. Há, pois, habilidades e competências que podem ser muito bem desenvolvidas pelas escolas, desde que

\section{MÉTODOLOGIA}

A abordagem metodológica da qual se fundamentou este trabalho procede de revisão de literatura não sistemática, cujas

\section{RESULTADOS E DISCUSSÕES}

Considerando a necessidade de o setor saúde dispor de uma política devidamente expressa relacionada à alimentação e nutrição, em consonância com a promoção da segurança alimentar e nutricional e que contribua para a garantia do direito à alimentação; Considerando a conclusão do processo de atualização da referida política, que envolveu consultas a diferentes segmentos direta e indiretamente envolvidos com o tema; e Considerando a aprovação da atualização proposta da política mencionada pela Comissão Intergestores Tripartite; resolve:

Art. $1^{\circ}$ Aprova a Política Nacional de Alimentação e Nutrição, cuja íntegra se encontra disponível no site eletrônico http://nutricao.saude.gov.br.

Art. $2^{\circ}$ Determinar que os órgãos e entidades do Ministério da Saúde, cujas ações se relacionem com o tema objeto da Política ora aprovada, promovam a tenham compromisso com a aprendizagem e desenvolvimento pleno de seus educandos buscam cumprir seu papel efetivamente.

fontes de pesquisas foram artigos científicos, livros e documentos de caráter público publicados no Diário Oficial da União.

\section{$\mathbf{Z}$}

elaboração ou a readequação de seus planos, programas, projetos e atividades na conformidade das diretrizes e responsabilidades nela estabelecidas (BRASIL, 2013).

Retratando a evolução do direito humano à alimentação, Flávio Luiz Schieck Valente conceituou a segurança alimentar e nutricional da seguinte forma:

\begin{abstract}
"Segurança alimentar e nutricional consiste em garantir a todos condições de acesso a alimentos básicos, seguros e de qualidade, em quantidade suficiente, de modo permanente e sem comprometer o acesso a outras necessidades essenciais, com base em práticas alimentares saudáveis, contribuindo assim para uma existência digna em um contexto de desenvolvimento integral da pessoa humana." (VALENTE, 2012).
\end{abstract}

David Diniz Dantas ao analisar a justiça brasileira e a necessidade de sua humanização, comenta que:

"Não adianta incluir na Constituição princípios lindos de justiça social, dignidade da pessoa humana, proteção aos pobres, solidariedade, se eu não os 
concretizo, se não os trago para o discurso judicial, se continuo aplicando o legalismo formal." (DANTAS, 2007).

Na saúde, ressalta-se a publicação do Decreto 7.508, de 28/06/2011, que regulamenta a Lei 8.080, com a instituição da Rede de Atenção à Saúde e dos Protocolos Clínicos e Diretrizes Terapêuticas, que possibilitarão avanços para a organização e oferta das ações de Alimentação e Nutrição no âmbito do SUS (BRASIL, 2013).

\section{A Lei Orgânica de Segurança Alimentar e Nutricional}

A Lei Orgânica de Segurança Alimentar e Nutricional (LOSAN - $\mathrm{n}^{\circ}$ 11.346) foi sancionada pelo Presidente Luiz Inácio Lula da Silva, em 15 de setembro de 2006, criando o Sistema Nacional de Segurança Alimentar e Nutricional (SISAN). A citada Lei estabelece como dever do Estado brasileiro formular e implementar "políticas, planos, programas e ações com vistas em assegurar o direito humano à alimentação adequada" (Art. $1^{\circ}$ ). $\mathrm{O}$ direito humano à alimentação adequada se apresenta como emanação da dignidade da pessoa humana e indispensável à concretização dos direitos consagrados na Constituição Federal (Art. $2^{\circ}$ ).

Conceitua a segurança alimentar e nutricional como direito de todos ao acesso regular, permanente, de qualidade, em quantidade suficiente, respeitando a diversidade cultural de cada região (Art. $3^{\circ}$ ). Assim, a segurança alimentar e nutricional não pode comprometer o acesso a outras necessidades essenciais, tais como a moradia, educação, saúde, lazer, vestuário, higiene, transporte e previdência social, conforme o Art. $7^{\circ}$, IV, da Constituição Federal.

Incluem-se como integrantes da segurança alimentar e nutricional (Art. $4^{\circ}$ ); dentre outros, a água, a geração de emprego, a redistribuição de renda (I); a conservação da biodiversidade e a utilização sustentável dos recursos (II); a promoção da saúde, da nutrição e da alimentação da população em geral e grupos em situação de vulnerabilidade social (III); a exigência de garantia de qualidade biológica, sanitária, nutricional e tecnológica dos alimentos (IV), bem como a comercialização e consumo de alimentos devem respeitar as características culturais do País (VI).

A soberania aparece como princípio norteador na conservação do direito à alimentação adequada e à segurança alimentar e nutricional, no sentido de que cabe a cada país decidir sobre a produção e consumo de alimentos (Art. $5^{\circ}$ ).

A cooperação técnica internacional deve nortear a ação do Estado brasileiro para promover a realização do direito humano à alimentação adequada (Art. $6^{\circ}$ ). 
O Sistema Nacional de Segurança Alimentar e Nutricional é integrado por um conjunto de órgãos e entidades da União, Estados e Distrito Federal e dos Municípios e pelas instituições privadas, com ou sem fins lucrativos, afetas à segurança alimentar e nutricional e que tenham interesse em aderir ao Sistema. (PLANALTO, 2006).

\section{Lei de Segurança Alimentar e Nutricional}

Esta lei cria o Sistema Nacional de Segurança Alimentar e Nutricional. SISAN com vistas em assegurar o direito humano à alimentação adequada. O Capítulo I fala das Disposições Gerais a seguir:

"Art. $1^{\circ}$ Esta Lei estabelece as definições, princípios, diretrizes, objetivos e composição do Sistema Nacional de Segurança Alimentar e Nutricional.

SISAN, por meio do qual o poder público, com a participação da sociedade civil organizada, formulará e implementará políticas, planos, programas e ações com vistas em assegurar o direito humano à alimentação adequada.

Art. $2^{\circ}$ A alimentação adequada é direito fundamental do ser humano, inerente à dignidade da pessoa humana e indispensável à realização dos direitos consagrados na Constituição Federal, devendo o poder público adotar as políticas e ações que se façam necessárias para promover e garantir a segurança alimentar e nutricional da população.

Art. $3^{\circ}$ A segurança alimentar e nutricional consiste na realização do direito de todos ao acesso regular e permanente a alimentos de qualidade, em quantidade suficiente, sem comprometer o acesso a outras necessidades essenciais, tendo como base práticas alimentares promotoras de saúde que respeitem a diversidade cultural e que sejam ambiental, cultural, econômica e socialmente sustentáveis." (PLANALTO, 2006).

Ainda no Capítulo I das Disposições Gerais, conforme a Lei de Segurança

Alimentar e Nutricional apresenta no:

“Art. 4 ${ }^{\circ}$ A segurança alimentar e nutricional abrange:

I. A ampliação das condições de acesso aos alimentos por meio da produção, em especial da agricultura tradicional e familiar, do processamento, da industrialização, da comercialização, incluindo-se os acordos internacionais, do abastecimento e da distribuição dos alimentos, incluindo-se a água, bem como da geração de emprego e da redistribuição da renda;

II. A conservação da biodiversidade e a utilização sustentável dos recursos;

III. a promoção da saúde, da nutrição e da alimentação da população, incluindo-se grupos populacionais específicos e populações em situação de vulnerabilidade social;

IV. A garantia da qualidade biológica, sanitária, nutricional e tecnológica dos alimentos, bem como seu aproveitamento, estimulando práticas alimentares e estilos de vida saudáveis que respeitem a diversidade étnica e racial e cultural da população;

V. A produção de conhecimento e o acesso à informação; e

VI. A implementação de políticas públicas e estratégias sustentáveis e participativas de produção, comercialização e consumo de alimentos, respeitando-se as múltiplas características culturais do País.

Art. $5^{\circ}$ A consecução do direito humano à alimentação adequada e da segurança alimentar e nutricional requer $\mathrm{o}$ respeito à soberania, que confere aos países a primazia de suas decisões sobre a produção e $\mathrm{o}$ consumo de alimentos.

Art. $6^{\circ} \mathrm{O}$ Estado brasileiro deve empenhar-se na promoção de 
cooperação técnica com países estrangeiros, contribuindo assim para a realização do direito humano à alimentação adequada no plano internacional." (PLANALTO, 2006).

\section{Política Nacional de Segurança Alimentar e Nutricional - PNSAN}

$\mathrm{O}$ Decreto $\mathrm{N}^{\mathrm{o}} 7.272$, de 25 de Agosto de 2010 regulamenta a Lei $n^{\circ}$ 11.346, de 15 de setembro de 2006, que cria o Sistema Nacional de Segurança Alimentar e Nutricional - SISAN com vistas a assegurar o direito humano à alimentação adequada, institui a Política Nacional de Segurança Alimentar e Nutricional PNSAN, estabelece os parâmetros para a elaboração do Plano Nacional de Segurança Alimentar e Nutricional, e dá outras providências.

O Presidente da República, no uso das atribuições que lhe confere o art. 84, incisos IV e VI, alínea "a", e tendo em vista o disposto no art. $6^{\circ}$, ambos da Constituição, e no art. $2^{\circ}$ da Lei 11.346 , de $15 \mathrm{n}^{\circ}$ de setembro de 2006, decreta: capítulo I e II das disposições preliminares:

\footnotetext{
"Art. $1^{\circ}$ Este Decreto define as diretrizes e objetivos da Política Nacional de Segurança Alimentar e Nutricional - PNSAN, dispõe sobre a sua gestão, mecanismos de financiamento, monitoramento $\mathrm{e}$ avaliação, no âmbito do Sistema Nacional de Segurança Alimentar e Nutricional - SISAN, e estabelece os parâmetros para a elaboração do Plano Nacional de Segurança Alimentar e Nutricional.
}

Art. 2 ${ }^{\circ}$ Fica instituída a Política Nacional de Segurança Alimentar e

Nutricional - PNSAN, com o objetivo geral de promover a segurança alimentar e nutricional, na forma do art. $3^{\circ}$ da Lei $n^{\circ} 11.346$, de 15 de setembro de 2006, bem como assegurar o direito humano à alimentação adequada em todo território nacional.

Art. $3^{\circ}$ A PNSAN tem como base as seguintes diretrizes, que orientarão a elaboração do Plano Nacional de Segurança Alimentar e Nutricional:

I - promoção do acesso universal à alimentação adequada e saudável, com prioridade para as famílias e pessoas em situação de insegurança alimentar e nutricional;

II - promoção do abastecimento e estruturação de sistemas sustentáveis e descentralizados, de base agroecológica, de produção, extração, processamento e distribuição de alimentos;

III - instituição de processos permanentes de educação alimentar e nutricional, pesquisa e formação nas áreas de segurança alimentar e nutricional e do direito humano à alimentação adequada;

IV - promoção, universalização e coordenação das ações de segurança alimentar e nutricional voltadas para quilombolas e demais povos e comunidades tradicionais de que trata $\mathrm{o}$ art. $3^{\circ}$, inciso I, do Decreto $\mathrm{n}^{\circ} 6.040$, de 7 de fevereiro de 2007, povos indígenas e assentados da reforma agrária;

$\mathrm{V}$ - fortalecimento das ações de alimentação e nutrição em todos os níveis da atenção à saúde, de modo articulado às demais ações de segurança alimentar e nutricional." (PLANALTO, 2010).

\section{Políticas Públicas de Segurança Alimentar e Nutricional}

No caso das políticas públicas de segurança alimentar e nutricional, os 
espaços institucionais formais de deliberação das políticas estão distribuídas em um grande número de órgãos, entidades e organizações na esfera da Administração Pública (Ministérios e Secretarias de diversas temáticas, tais como, Assistência Social, Abastecimento, Agricultura, Saúde) e da sociedade civil organizada. A natureza multidimensional do direito humano à alimentação - ou seja, o reconhecimento que a alimentação se relaciona de forma interdependente com as dimensões ambientais, culturais, nutricionais e econômicas - impõe um arranjo organizacional também diversificado, seja no âmbito da estrutura burocrática ou dos próprios movimentos sociais.

Algumas políticas públicas visam garantir o direito à alimentação no Brasil Para fins desse trabalho, a ANVISA foi escolhida como arena política a ser estudada como espaço de deliberação das políticas públicas direcionadas às pessoas com necessidades alimentares especiais.

No biênio 2015-2016, a Agência publicou nova agenda no qual a rotulagem é também inserida, mas agora com a

\section{CONSIDERAÇÕES FINAIS}

Segundo informação inegável da realidade brasileira nos últimos tempos pode-se afirmar que a carência alimentar e nutricional implica seriamente o classificação de alta relevância, urgência e complexidade.

$\mathrm{Na}$ justificativa da atuação regulatória, a ANVISA determina que:

"A proposta de declaração obrigatória
de rotulagem de alergênicos em
alimentos é considerada uma medida
essencial para proteger a saúde dos
consumidores. Dada a sua
importância, o tema está previsto nos
padrões do Codex Alimentarius e
também é regulamentado pelo
Canadá, Estados Unidos, União
Europeia, Austrália e Nova Zelândia.
É necessário revisar a RDC n 259 , de
20 de setembro de 2002, que
regulamenta o assunto, para garantir
aos consumidores rótulos com
informações claras e precisas sobre a
composição dos alimentos."
(ANVISA, 2015, p. 102).

Em junho de 2014, a ANVISA abriu o prazo para a Consulta Pública (CP 29/14) com o objetivo de receber contribuições da sociedade civil sobre o tema. Em 06 de maio de 2015, a ANVISA realizou a audiência pública com o objetivo de recolher informações sobre o tema, bem como discutir as alterações propostas no texto de acordo com a Consulta Pública. A Resolução RDC 26 foi finalmente publicada em 02 de julho daquele ano, com previsão de um prazo de adequação de um ano (ANVISA, 2015).

desenvolvimento da criança, do adolescente, do adulto e principalmente do idoso de tal forma que, por toda a vida, sofrerão os resultados de uma inadequada alimentação, de hábitos saudáveis, 
atingindo-os não só nos aspectos físicos, mas também emocionais e intelectuais.

Em meio aos contrastes, o qual vive o Brasil é preciso despertar com urgência para a peleja e o cumprimento dos direitos fundamentais, começando com a garantia de políticas sociais públicas, porque somente elas podem garantir direitos básicos sem os quais não há imperativo de ponderar sobre a dignidade humana.

Sem uma alimentação adequada o povo não tem esperança e não há garantia da vida. Por isso é preciso garantir o caminho que leva a todos os direitos

\section{REFERÊNCIAS}

ANVISA. Alimentos e alergia: participe da Consulta Pública. 2015. Disponível em: $<$ http://portal.anvisa.gov.br/noticias//asset_publisher/FXrpx9qY7FbU/ content/alimentos-e-alergia-participe-daconsulta-publica/219201/

pop_up?_101>. Acesso em 11/11/2019.

BRASIL. Ministério da Saúde. Secretaria de Atenção à Saúde. Departamento de Atenção Básica. Política Nacional de Alimentação e Nutrição. Ministério da Saúde, Secretaria de Atenção à Saúde. Departamento de Atenção Básica. Ed.1 - Brasília: Ministério da Saúde, 2013.

DANTAS, D. D. A humanização da justiça. Revista ISTOÉ, no 1804, 5/5/2004. LAVOR, Adriano De. Um padrão bem pouco saudável. FIOCRUZ, Revista RADIS n ${ }^{\circ}$, Rio de Janeiro, abr/2007.

DELDUQUE, M.C. et al. $O$ direito à alimentação nos tribunais: uma análise. fundamentais previstos nas legislações abordadas. É preciso melhorar a relação entre esses campos, saúde e direito, pois os poderes devem ser contrabalançados com o diálogo, e os gestores públicos desempenham um papel fundamental no desencadeamento desse processo.

Note-se também que protocolos e leis precisam ser adequados às necessidades de saúde das pessoas, e não o contrário; e aplicar as garantias legais incorporadas na Constituição Federal ainda é um grande desafio para os gestores.

Demetra, Rio de Janeiro, vol. 9, nº 1, p.393408.

DIÁRIO OFICIAL DA UNIÃO. Lei $n .8080$ de 19 de setembro de 1990. Dispõe sobre as condições para a promoção, proteção e recuperação da saúde, a organização e o funcionamento dos serviços correspondentes e das outras providências.

DIAS, P. R. P. Direito à saúde: demanda por suplementos alimentares no tribunal de justiça de Minas Gerais. Cad. Ibero-Amer. Dir. Sanit. Brasília, v. 4, n. 3, p.39-51, 2015.

LEÃO, M. M. III Conferência Nacional de Segurança Alimentar e Nutricional, Documento Final, 2007, p. 24. Acessado em: 11/11/2019. Disponível em: <http://www.mds.gov.br/webarquivos/publica cao/seguranca_alimentar/DHAA_SAN.pdf $>$.

MACEDO et al. A construção da política de segurança alimentar e nutricional no Brasil. Simbio-Logias, vol.2, n1, p. 31-46 
MINISTÉRIO DA SAÚDE. Secretaria de Atenção à Saúde. Departamento de Atenção Básica. Portaria $N^{\circ} 2.715$, de 17 de novembro de 2011 - Atualiza a Política Nacional de Alimentação e Nutrição. Brasília (Brasil): Ministério da Saúde; 2011.

PLANALTO. (2006). Lei de Segurança Alimentar e Nutricional. Acessado em: 12/12/2019. Disponível em: $<$ http://www4.planalto.gov.br/consea/conferen cia/documentos/lei-de-seguranca-alimentar-enutricional>.

SAUDE. Política Nacional de Alimentação e Nutrição. Acessado em: 15/11/2019.

Disponível em:

<httpbvsms.saude.gov.brbvspublicacoespolitic a_nacional_alimentacao_nutricao.pdf >
SENADO FEDERAL. Constituição 1988. Constituição da República Federativa do Brasil. Brasília: Senado Federal; 1988. Acessado em 10/11/2019.

SISSON, M. C. Considerações sobre o programa de saúde da família e a promoção de maior equidade na política de saúde. Revista Saúde e Sociedade, v. 16, n. 3, set./dez. 2007. Acessado em: 11/11/2019. Disponível em: $<$ https://www.fen.ufg.br/revista/v14/n1/pdf/v1 4n1a08.pdf $>$.

VALENTE, F. L. S. Direito Humano à Alimentação: desafios e conquistas. São Paulo: Cortez, 2012. 